\title{
LOSS MODELING OF A PERMANENT MAGNET DC MOTOR DRIVE WATER PUMPING SYSTEM
}

\author{
Nelson K. Lujara \\ Department of Electrical Power Engineering, \\ University of Dar es Salaam, P.O. Box 35131, Dar es Salaam. \\ Email: lujara@udsm.ac.tz
}

\begin{abstract}
The paper presents an analytical approach to the determination of losses in each of the sub-systems of the Photovoltaic (PV) Permanent Magnet DC Motor (PMDC) drive water pumping system with and without maximum power tracking. The losses of the system at varying heads are firstly, determined using parameters from the data sheets and then validated by experimental results. The results are used to establish the head and the flow rate optimal operating point of the system.
\end{abstract}

Key words: Permanent Magnet DC Motor, Photovoltaic, Losses, Maximum Power Tracker, Water Pumping.

\section{INTRODUCTION}

There are three ways of improving the efficiency of direct-coupled PV systems commonly in use: Fitting PV generators with sun-trackers (Gay, 1982; Lynch et al., 1988; Moshov, 1977; Dione, 2004) by carefully selecting the components of the systems to produce a good match between the solar array and the load (Hsiao et al., 1984; Roger, 1979; HadjArab, 2004) and by connecting a maximum power tracker (MPT) between the PV array and the load. The advantages and the disadvantages associated with each method are well known and can be found in (Lujara, 1999). In this paper a permanent magnet dc motor drive water pumping system with and without MPT at a fixed insolation are investigated. The detailed calculations of losses for each component are analyzed and presented.

\section{SYSTEM ARRANGEMENT}

Two set up were investigated: The PV system without MPT, which included a set of solar modules, a permanent magnet dc (PMDC) motor and a rotary pump. The system with MPT consisted of either a buck or a boost converter connected between the solar modules and the motor to force the array to operate at maximum power point. The rated values for the PMDC motor were: $0.5 \mathrm{hp}, 1750 \mathrm{rpm}, 90$ $\mathrm{V}$ and $4.8 \mathrm{~A}$. The permanent magnet dc motor was connected to the pump via a pulley of ratio $1: 2$ and a toothed flat belt. The pump had a minimum starting torque of $3 \mathrm{Nm}$ and a maximum speed of $333 \mathrm{~cm}^{3} / \mathrm{sec}$.

\section{Loss and Efficiency Calculations}

PV Array

The efficiency of the PV array at a constant insolation of $1200 \mathrm{~W} / \mathrm{m}^{2}$ was obtained from;

$\eta_{a}=\frac{V_{p} \cdot I_{p}}{P}$

$P=S \times A$

Where;

$P=$ Irradiation power

$S=$ Measured insolation 
$A=$ Array cross-section area

$V_{p}=$ Array output voltage

$I_{p}=$ Array output current

$V_{p}$ and $I_{p}$ were obtained from the $\mathrm{V}-\mathrm{I}$

characteristic curve of the PV array (Lujara, 1999).

\section{DC-DC Converter}

Two types of dc-dc converters were used as maximum power trackers: the buck and the boost converter. The losses which were modelled are: conduction losses in the switch and freewheeling diode, switching losses in the switch and freewheeling diode, resistive losses in the inductance, snubber losses, gate drive losses and core losses.

\section{Conduction Losses of the Switch}

When the MOSFET is conducting, the power dissipation during that period is given by:

$$
P_{C}=i_{s}^{2} \times R_{D S(O N)}
$$

Where,

$i_{s}=$ The rms drain current

$R_{D S(O N)}=$ The drain-to-source resistance at junction temperature

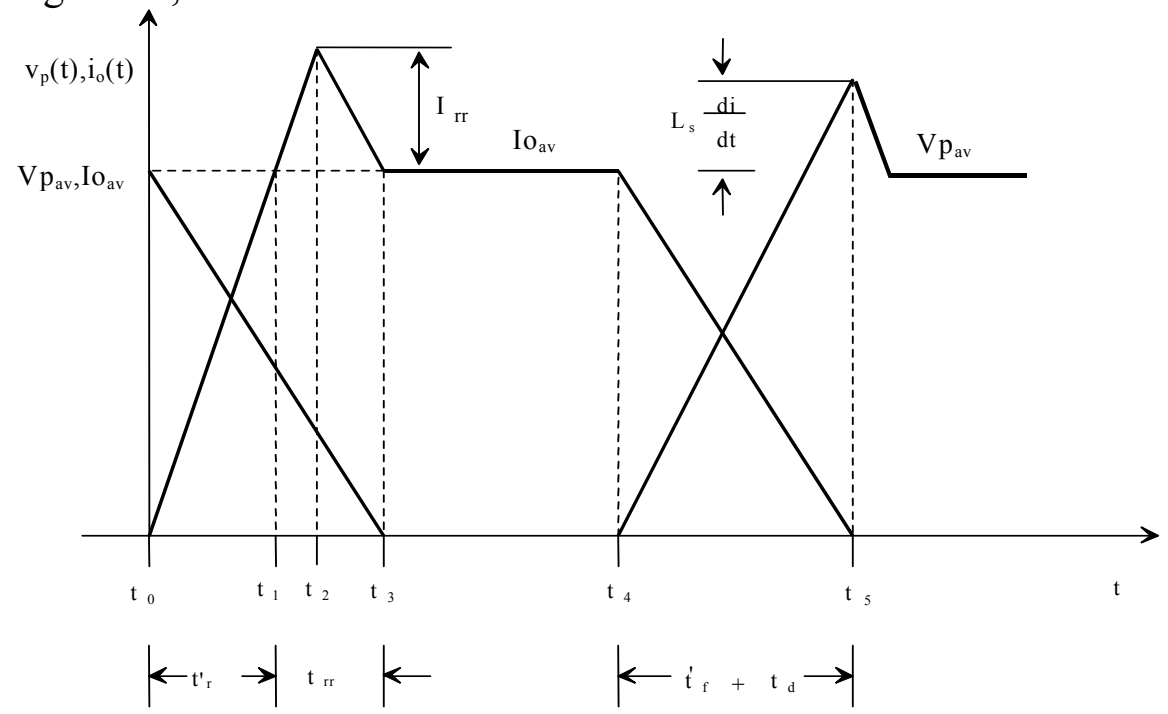

Figure 1: Turn-on and off characteristics of a buck converter

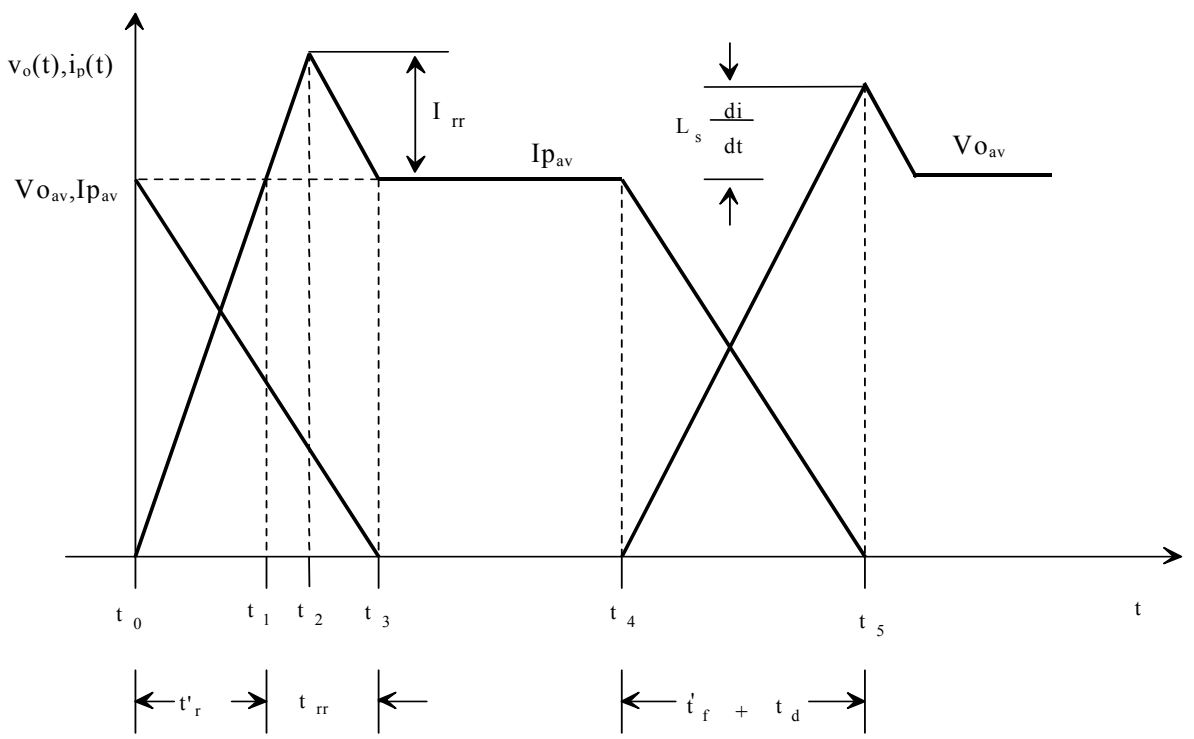

Figure 2: Turn-ON and OFF characteristics of a boost converter 
$R_{D S(O N)}=R_{D S(O N)}\left(25^{\circ}\right) \cdot\left(1+\frac{\alpha}{100}\right)^{T_{j}-25}$

Where;

$R_{D S(O N)}\left(25^{\circ}\right)=$ Drain to source resistance at $25^{\circ} \mathrm{C}$

$\alpha=$ Factor relating the junction temperature and the drain to source resistance

$T_{j}=$ Junction temperature

\section{Switching Losses in the MOSFET}

The switching losses constitute the turnON losses and the turn-OFF losses. The turn-ON transient includes the current rise time, voltage fall time and diode recovery time. The turn-OFF characteristic consists of the current fall time and the turn-OFF delay time. Fig. 1 and Fig. 2 show the approximate turn-ON and turn-OFF transients of the MOSFET for the buck and boost converters, respectively.

Turn-On Losses

$\boldsymbol{t}_{\boldsymbol{0}} \leq \boldsymbol{t} \leq \boldsymbol{t}_{\mathbf{1}}$

For buck converter, the average turn-ON losses were evaluated using the following relationship:

$P_{a v}=f_{s} \cdot \int_{0}^{t_{r}}\left(\left[V_{P_{a v}}-V_{P_{a v}} \cdot \frac{t}{t_{t}}\right] \cdot I_{O_{a v}} \cdot \frac{t}{t_{r}^{\prime}}\right) d t$

Where $f_{s}=$ Switching frequency, $V_{P_{a v}}=$ Average input voltage, $I_{O_{0 v}}=$ Average output current, $t_{r}{ }^{\prime}=$ Current rise time, $t_{r r}=$ Reverse recovery time of the freewheeling diode.

$$
t_{t}=t_{r}^{\prime}+t_{r r}
$$

The turn-ON losses in the boost converter were also calculated using equation (5) with the average load voltage, $V_{o_{\omega}}$ and the average input current, $I_{p_{a v}}$ replacing the average input voltage and output current, respectively.

$\boldsymbol{t}_{\mathbf{1}} \leq \boldsymbol{t} \leq \boldsymbol{t}_{\mathbf{2}}$

For the period $t_{1}-t_{2}=t_{a}$, the average losses in the buck and boost converters were determined using (6) and (7), respectively,

$$
\begin{aligned}
& P_{a v}=f_{s} \cdot \int_{t_{r}}^{t_{r a}}\left(\left[V_{P_{a v}}-V_{P_{a v}} \cdot \frac{t}{t_{t}}\right] \cdot I_{O_{a v}} \cdot \frac{t}{t_{r}^{\prime}}\right) d t \\
& P_{a v}=f_{s} \cdot \int_{t_{r}}^{t_{r a}}\left(\left[V_{O_{a v}}-V_{O_{a v}} \cdot \frac{t}{t_{t}}\right] \cdot I_{P_{a v}} \cdot \frac{t}{t_{r}^{\prime}}\right) d t
\end{aligned}
$$

Where;

$$
\boldsymbol{t}_{2} \leq \boldsymbol{t} \leq \boldsymbol{t}_{3}
$$

$$
t_{r a}=t^{\prime}{ }_{r}+t_{a}
$$

For the time $t_{2}-t_{3}\left(t_{b}\right)$, the average losses for the buck converter were calculated using:

$P_{a v}=f_{s} \cdot \int_{0}^{t_{b}}\left(\left[V_{p_{a v}}{ }-V_{p_{a v}}^{\prime} \cdot \frac{t}{t_{b}}\right] \cdot I_{O_{a v}}^{\prime \prime} \frac{t}{t_{b}}+I_{o_{a v}}^{\prime}\right) d t$

where;

$$
\begin{aligned}
& V_{P_{a v}^{\prime}}^{\prime}=V_{P_{a v}}-V_{P_{a v}} \cdot \frac{t_{r a}}{t_{t}} \\
& I_{O_{a v}}^{\prime}=I_{o_{a v}} \cdot \frac{t_{r a}}{t_{r}^{\prime}} \\
& I_{O_{a v}}^{\prime \prime}=I_{O_{a v}}-I_{O a v}^{\prime}
\end{aligned}
$$

Like in the previous evaluation, $V_{P_{a v}}$ and $I_{O_{a v}}$ of (8) are replaced by $V_{O_{a v}}$ and $I_{P_{a v}}$ respectively for the calculation of losses in the boost converter. The total turn-ON losses are obtained by the summation of average losses in the periods from $t_{0}-t_{3}$.

\section{Turn-Off Losses}

During turn-OFF switching at $t=t_{4}$ in Fig. 1 and Fig. 2, the voltage across the switch rises and the current falls linearly immediately, after the turn OFF process is initiated. The current in the MOSFET decreases at the rate dictated by the MOSFET properties and its gate drive as well as the load power factor.

For the buck converter, the voltage across the MOSFET is expressed as;

$V=V_{P_{a v}}-L_{S} \frac{d i}{d t}$

and for the boost converter, 


$$
V=V_{O_{a v}}-L_{S} \frac{d i}{d t}
$$

Where;

$$
\begin{aligned}
& \frac{d i}{d t}=\text { The rate of change of current } \\
& L_{s}=\text { Stray inductance }
\end{aligned}
$$

Since $\frac{d i}{d t}$ is negative, the presence of stray inductance results in over-voltages.

At the end of $t_{4}$ (i.e. at $t_{5}$ ) the voltages falls to the average input and output voltages for the buck and boost converters, respectively. The average losses in the period $t_{4}-t_{5}$ are determined using the following procedure: the actual time that the current has to fall from the load current to zero is given by;

$$
t_{t}=t_{f}^{\prime}+t_{d}
$$

Where;

$$
\begin{aligned}
& t_{f}^{\prime}=\text { Current fall time } \\
& t_{d}=\text { Current turn-OFF delay time }
\end{aligned}
$$

Average power loss during this period is determined from (11) by substituting appropriate values of current and voltage for the buck and boost converters.

$$
P_{a v}=f_{S} \int_{0}^{t_{t}}\left(V+L_{S} \frac{d i}{d t} \cdot \frac{t}{t_{t}}\right) \cdot\left(I-I \cdot \frac{t}{t_{t}}\right) d t
$$

\section{Conduction Losses in the Freewheeling Diode}

At low current and power levels which are typical of dc-dc converters for PV applications, the ON-state voltage of the freewheeling diode is assumed to be approximately constant because the voltage varies logarithmically with the diode current (Mohan et al., 1995). The power dissipation in the drift region of the diode is also ignored because the effective resistance of this region during its $\mathrm{ON}$ state condition is much less than the apparent value determined using the geometrical size and the thermal equilibrium carrier densities (Mohan et al., 1995). The ON-state dissipation is thus estimated from;
$P_{C}=V_{o n} \cdot I_{f_{a v}}$

Where;

$V_{\text {on }}=$ ON-state voltage of the freewheeling diode and $I_{f_{a v}}=$ Average current flowing in the freewheeling diode

\section{Switching Losses in the Freewheeling Diode}

The approximate turn-ON and OFF transients of the freewheeling diode are shown in Fig. 3. At low current levels, the losses associated with the turn-ON transient are neglected since the turn-ON time of the freewheeling diode is negligible. The turn-OFF losses during time $t_{a}$ are also negligible since the voltage across the freewheeling diode during that period is essentially the ONstate voltage of the diode. This means the switching losses of the diode are calculated during the reverse recovery period, $t_{b}$ using (13);

$$
P_{a v}=f_{s} \cdot \int_{0}^{t_{b}} V_{R} \cdot\left(I_{r r}-I_{r r} \frac{t}{t_{b}}\right) d t
$$

Where;

current

$$
\begin{aligned}
& t_{b}=t_{r r}-t_{a} \\
& I_{r r}=\text { Peak reverse recovery }
\end{aligned}
$$

$$
V_{R}=\text { Peak reverse voltage }
$$

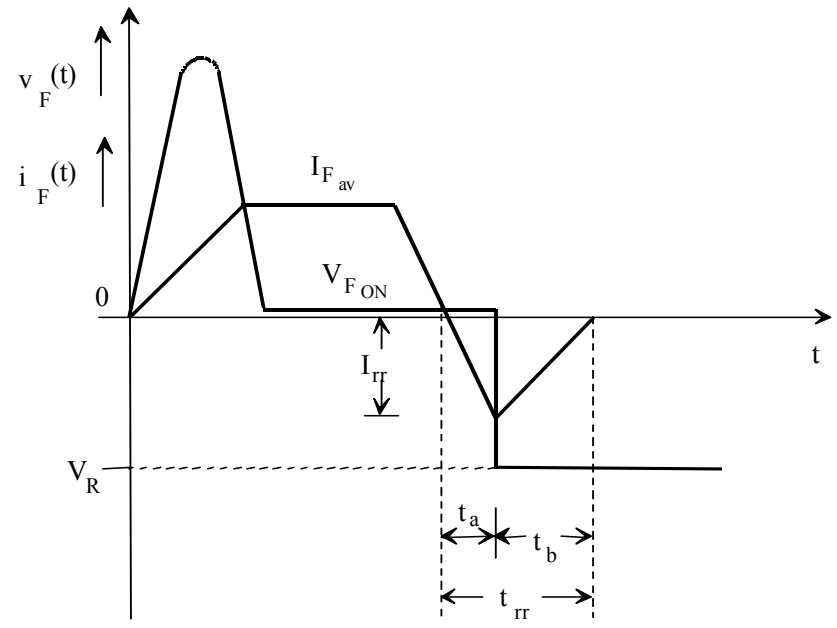

Figure 3: Turn-on and off transient characteristics of the freewheeling diode 


\section{Resistive Losses in the Inductor}

$P_{R}=I_{d c}^{2} R_{d c}+I_{r m s}^{2} R_{a c}$

Where $I_{d c}=\mathrm{dc}$ component of current flowing in the inductor, $R_{d c}=$ the $\mathrm{dc}$ resistance of the inductor, $I_{r m s}=\mathrm{rms}$ ac component of current flowing in the inductor, $R_{a c}=$ resistance of the inductance at switching frequency.

\section{Core Losses}

The core losses produced in the magnetic material of the inductor are separated into two components: hysteresis and eddy current losses.

\section{Hysteresis Losses}

Losses due to molecular friction as the particles of the core tend to align themselves. Hysteresis losses are obtained from (15) (Kenjo et al., 1985, Say and Taylor, 1982);

$P_{h}=\eta \cdot B^{n} \cdot f \quad\left[\frac{W}{m^{3}}\right]$

Where $\eta=$ Material constant,

$B=$ Maximum flux density,

$f=$ Frequency and

$n=$ Material constant.

\section{Eddy Current Losses}

The circulating currents induced in the magnetic material of the inductor produce power that is dissipated as heat. These losses are termed eddy currents and are determined using (16) (Kenjo et al., 1985; Say and Taylor, 1982);

$$
P_{e}=\frac{(\pi \cdot B \cdot t \cdot f)^{2}}{\rho \cdot \beta} \quad\left[\frac{W}{m^{3}}\right]
$$

Where; material

$t=$ Thickness of magnetic

$\rho=$ Resistivity of the material

$\beta=$ A coefficient which has different values for different geometries

\section{Resistive Losses in the Capacitors}

The resistive losses in the capacitor are determined using (17).
$P_{c}=I_{c_{r m s}}{ }^{2} \cdot R_{c}$

Where $I_{c_{r m s}}=$ rms current flowing in the capacitor and $R_{c}=$ Equivalent series resistance of the capacitor

\section{Losses in the Gate Drive}

The losses in the gate drive when MOSFET are used as switching devices are calculated when the switch capacitance is being charged or discharged. The calculation for these losses is thoroughly treated in (Lujara et al., 1999).

\section{The Motor}

The losses in a permanent magnet $\mathrm{dc}$ motor with a winding resistance, $R_{a}$ comprise of: copper losses, core losses, brush losses, mechanical losses and stray load losses.

- Copper losses: the armature copper loss, $P_{c u}$ is determined from the armature current $I_{a}$, and armature resistance, $R_{a}$.

- Brush losses, $P_{b}$ : for carbon brushes, the p.d. between the brushes and the commutator over a wide range of current is assumed to be $2 \mathrm{~V}$ (Hindmarsh, 1977; Kenjo et al., 1985) per set of brushes, so that the total contact resistance loss is given by;

$P_{b}=2 \cdot I_{a}$

- Mechanical losses: These losses were determined by directly coupling the motor to an auxiliary drive using a hard rubber coupling whose losses were assumed to be negligible. Mechanical losses were assumed to remain approximately constant at all heads. The resulting mechanical losses as a function of speed are shown in Figure 4. 


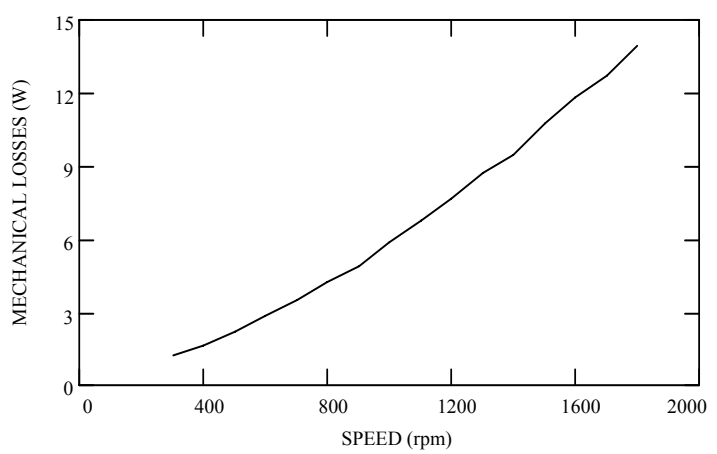

Figure 4: Mechanical losses of a permanent magnet dc motor

- Core losses: If the effect of armature reaction is neglected the core losses are assumed to remain constant at all loads at one speed. Core losses were established from the difference between the motor no-load losses (corrected for copper and brush losses) and the mechanical losses. Core losses, however were found to be negligible for the motor used.

- Stray load losses: These losses were assumed to be $1 \%$ of the basic output (Say and Taylor, 1982). The basic output is that corresponding to the rated current and rated voltage.

\section{Pump}

The efficiency of the pump including the motor-pump coupling losses was determined as follows:

The motor power output, $P_{o}$ was obtained from,

$P_{o}=P_{i}-P_{l}$

Where $P_{i}=$ Input power to the motor and $P_{l}=$ Total losses in the motor

The efficiency of the pump is expressed as,

$\eta_{p}=\frac{P_{p}}{P_{o}}$

Where;

$P_{p}=Q \cdot h \cdot g \cdot \rho$

$\mathrm{P}_{\mathrm{p}}=$ Pump power output, $\mathrm{Q}=$ Water flow rate, $\mathrm{h}=$ Head, $\mathrm{g}=$ Acceleration due to gravity, $\rho=$ The density of water.
The relationship between the head and the efficiency of the pump up to a head of 60 metres was established and plotted as shown in Fig. 5.

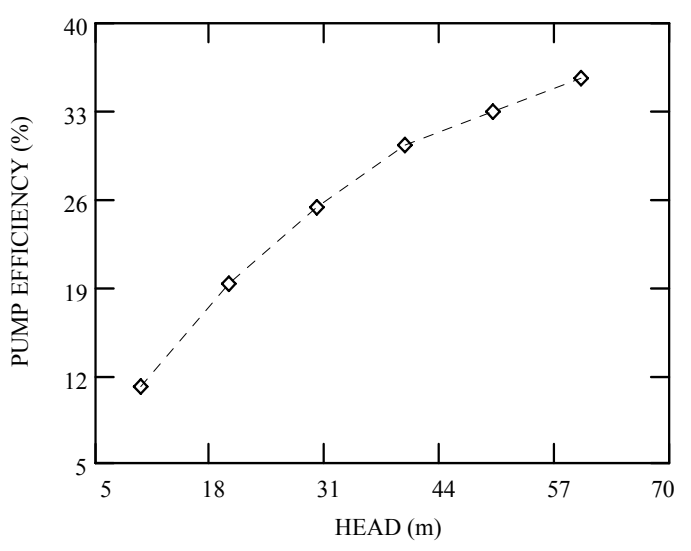

Figure 5: Efficiency of the pump against the head

\section{SIMULATION RESULTS}

\section{The System without MPT}

System simulation was performed using MathCAD at a testing insolation of 1200 $\mathrm{W} / \mathrm{m}^{2}$. The main input variable was the insolation and the output variables were the flow rate, the motor losses and the sub-system efficiencies. The control parameter was the head. The PV array was connected in two different configurations: the high voltage low current (HVLC) mode and the high current low voltage (HCLV) mode (Lujara, 1997, Demetrio, 2014, Kung Ding, 2014).

\section{PV Array}

Figure 6 shows the generator efficiency against the head in the HVLC and HCLV modes. It is observed that the array efficiency is below $10 \%$ and that there exists an optimal operating point of the array where the efficiency is maximum. Such point is beyond the head-operating region for the HCLV mode. 


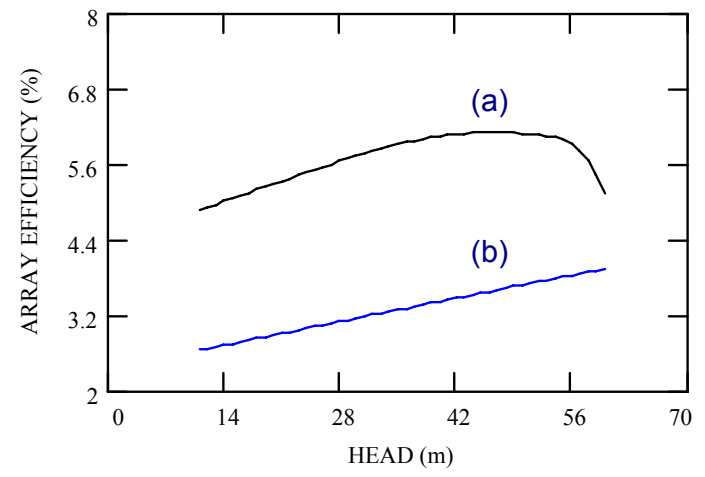

Figure 6: Array efficiency (a) HVLC mode (b)HCLV mode

\section{Motor}

The efficiency of the motor decrease with increasing head as shown in Fig. 7. The efficiency of the motor in the HCLV mode is much lower than in the HVLC mode because, for the same head, the dominant losses (copper losses) are equal but at a lower power input in the HVLC mode. The speed of the motor (equation 22) follows the array voltage curve since the voltage drop due to armature resistance is small (less than $10 \%$ in the operating range of the terminal voltage of the motor). The brush voltage drop, $V_{b}$ is negligible.

$\omega=\frac{V_{p}-I_{a} \cdot R_{a}-V_{b}}{k_{s}}$

Where $\omega=$ Motor angular speed, $V_{p}=$ Motor terminal voltage $=$ array output voltage, $k_{s}=$ Speed constant.

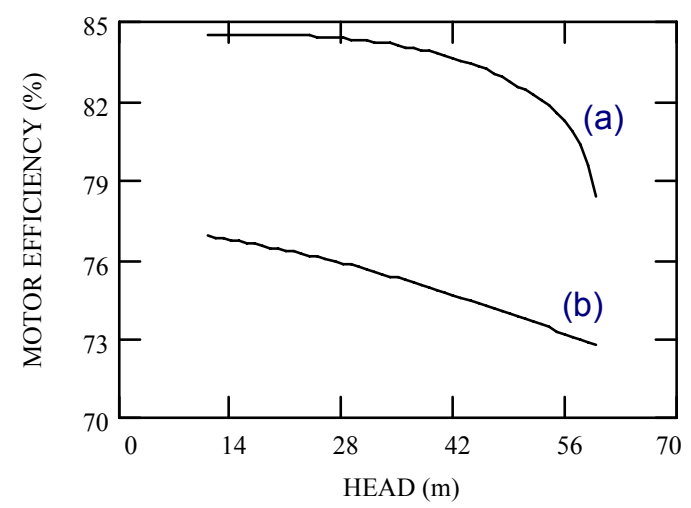

Figure 7: Efficiency of the motor (a) HVLC mode (b) HCLV mode
The System with Buck Converter as
MPT

Maximum Power Tracker

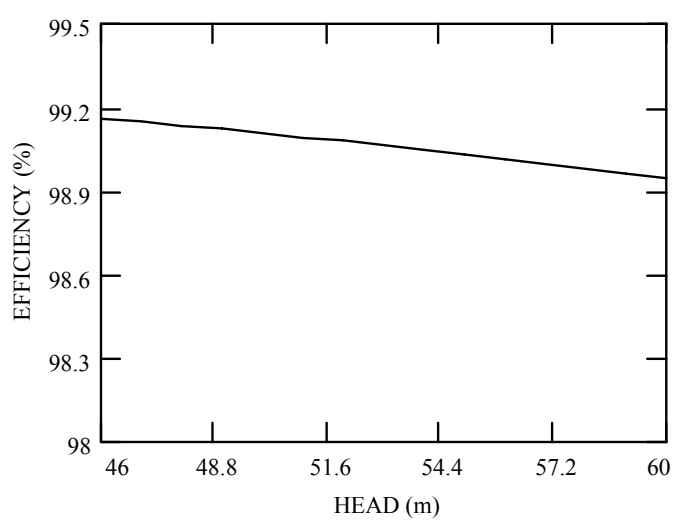

Figure 8: Efficiency of the maximum power tracker

Figure 9 shows the efficiency of the motor against the head in the operating range. The array is configured in the HVLC mode. Copper losses are dominant and therefore the efficiency of the motor is low at higher heads because the motor draws large current at higher heads.

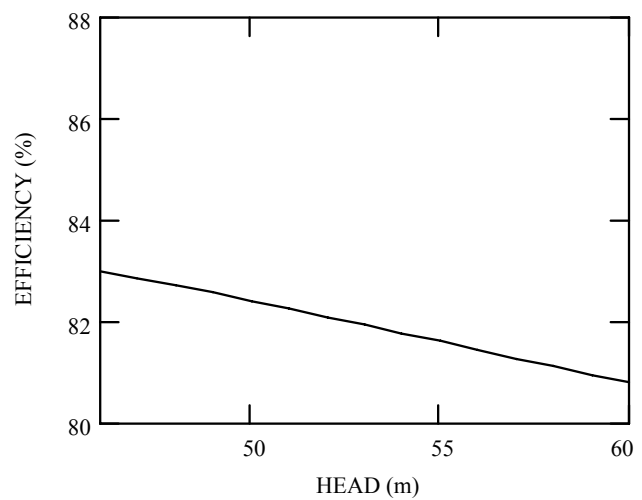

Figure 9: Efficiency of the motor

\section{The System with Boost Converter as $M P T$}

Maximum Power Tracker

Figure 10 shows the plot of the efficiency against the head when the boost converter is used as the maximum power tracking circuit. The efficiency of the boost converter is above $96 \%$ and the losses are less than $8 \mathrm{~W}$ at an output power of 240 W. 


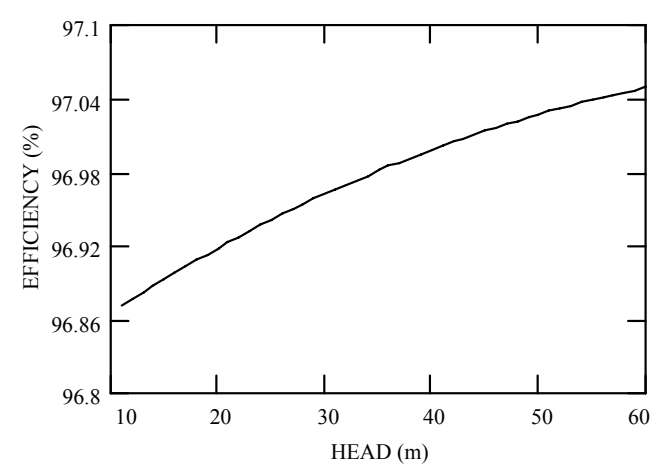

Figure 10: Efficiency of the boost converter

\section{Motor}

The efficiency of the motor is shown in Figure 11. At lower heads the speed of the motor is close to its rated speed and the motor efficiency is high.

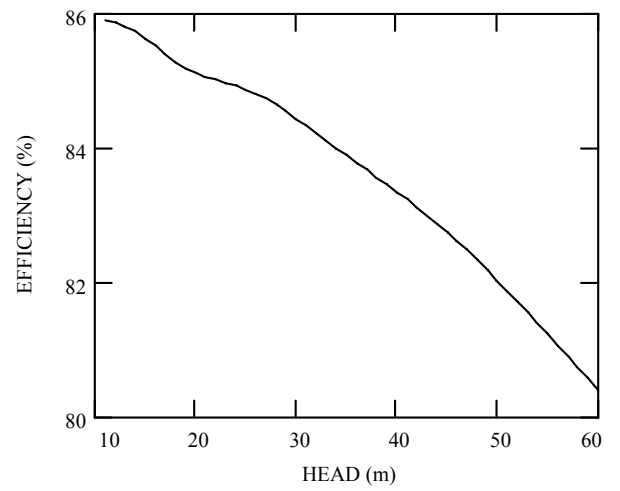

Figure 11: Efficiency of the motor

\section{Experimental Validation}

To be able to assess the validity of any developed simulation model, experimental measurements have to be done on the actual experimental set-up. If there is good correlation between the computed and the measured values, then accurate design of the system using the developed model is assumed. Measurements were done on each of the systems described in section 2.0. The PV array was replaced by a dc-power supply with the input current and voltage obtained from the V-I characteristic of the $\mathrm{PV}$ array at an insolation of $1200 \mathrm{~W} / \mathrm{m}^{2}$.

\section{The System without MPT}

In this system the motor speed and the flow rate of the system at variable head were measured. The experimental motor losses are obtained by measuring the input and output power of the motor. Table I presents the comparison between the simulated and experimental values. There is quite good agreement between the experimental and the simulated results with maximum error in various parameters not exceeding $6 \%$

Table 1: Simulation and experimental results of a PMDC motor drive WPS without MPT

\begin{tabular}{c|c|c|c|c|c|c|c|c|c} 
& \multicolumn{3}{|c|}{ Motor losses } & \multicolumn{3}{c|}{ Flow rate } & \multicolumn{3}{c}{ Motor speed } \\
\hline $\mathrm{H}$ & $P m_{s}$ & $P m_{e}$ & $\%$ er & $Q_{s}$ & $Q_{e}$ & $\%$ er & $n_{s}$ & $n_{e}$ & $\%$ er \\
\hline 10 & 23.79 & 24.6 & 3.4 & 88.95 & 84.72 & 5.8 & 651.73 & 622 & -4.9 \\
20 & 26.83 & 27.5 & 2.4 & 85.15 & 80.56 & 5.7 & 636.03 & 609 & -4.4 \\
30 & 30.18 & 31.2 & 3.3 & 81.17 & 77.78 & 4.4 & 619.96 & 591 & -4.9 \\
40 & 33.88 & 35.7 & 5.1 & 77.84 & 73.61 & 5.7 & 603.4 & 582 & -3.7 \\
50 & 37.92 & 39.0 & 2.8 & 72.04 & 69.45 & 3.7 & 586.4 & 560 & -4.7 \\
60 & 42.29 & 43.4 & 2.6 & 68.41 & 63.89 & 7.1 & 569.12 & 544 & -4.6
\end{tabular}

$\mathrm{H}=$ Pumping height in metres, $\mathrm{Pm}_{\mathrm{s}}=$ simulated motor losses $(\mathrm{W}), \mathrm{Pm}_{\mathrm{e}}=$ measured motor losses $(\mathrm{W}) \mathrm{Q}_{\mathrm{s}}=$ simulated flow rate $\left(\mathrm{cm}^{3} / \mathrm{sec}\right), \mathrm{Q}_{\mathrm{e}}=$ measured flow rate $\left(\mathrm{cm}^{3} / \mathrm{sec}\right), \mathrm{n}_{\mathrm{s}}=$ simulated speed (rpm)

$\mathrm{n}_{\mathrm{e}}=$ measured speed $(\mathrm{rpm}), \%$ er $=\%$ error $=\frac{\text { Measured value }- \text { Simulated value }}{\text { Measured value }}$ 


\section{The System with MPT}

In this system in additional to the parameters measured, the losses in the MPT were established. The results are shown in Table 2. The results show that there is good correlation between the simulated and experimental results with the simulated values on the higher side. The \% deviation between the simulated and the measured results does not exceed $6 \%$.

\section{CONCLUSION}

The acceptance of any simulation model is predicated upon the measurements on the actual system. This is because there are no simplifying assumptions in the measurements of the actual system, and therefore can be used as a true reference for calibration purposes. This paper has presented an analytical approach to the determination of losses in each of the subsystems of the PV permanent magnet dc motor drive water pumping system. The results have been validated by the good agreement between the measured and the simulated results. It is concluded that the system performance can be predicted using available data from manufacturer's data sheets or data on the machine's name plates and the load requirements.

Table 2: Simulation and experimental results of a PMDC motor drive WPS with MPT

\begin{tabular}{c|c|c|c|c|c|c|c|c|c|c|c|c} 
& \multicolumn{2}{|c|}{ MPT losse } & \multicolumn{3}{c|}{ Motor losses } & \multicolumn{3}{c|}{ Flow rate } & \multicolumn{3}{c}{ Motor speed } \\
\hline$H$ & $P p_{s}$ & $P p_{e}$ & $\%$ er & $P m_{s}$ & $P m_{e}$ & $\%$ er & $Q_{s}$ & $Q_{e}$ & $\%$ er & $n_{s}$ & $n_{e}$ & $\% e r$ \\
\hline 10 & 7.707 & 7.9 & 2.4 & 32.85 & 34.0 & 3.4 & 229.6 & 227.8 & -0.8 & 1687 & 1650 & -2.2 \\
20 & 7.578 & 7.8 & 2.8 & 34.68 & 35.8 & 3.1 & 199 & 197 & -0.93 & 1490 & 1452 & -2.6 \\
30 & 7.469 & 7.7 & 3 & 36.24 & 37.6 & 3.6 & 174 & 172 & -1.0 & 1343 & 1277 & -5.2 \\
40 & 7.38 & 7.5 & 2.9 & 38.82 & 40.1 & 3.2 & 153.6 & 152.8 & -0.51 & 1210 & 1178 & -2.7 \\
50 & 7.308 & 7.4 & 2.6 & 41.85 & 43.1 & 2.9 & 121.6 & 130.6 & -0.81 & 1095 & 1044 & -4.9 \\
60 & 7.252 & 7.3 & 2 & 45.65 & 47.2 & 3.3 & 116 & 115 & -0.75 & 995 & 951 & -4.6
\end{tabular}

$P p_{s}=$ simulated MPT losses $(W), P p_{e}=$ measured MPT losses $(W)$ 


\section{REFERENCES}

Gay C.F. (1982). Performance advantages two-axis tracking for large flat-plate photovoltaic energy systems. Sixteenth IEEE Photovoltaic Specialists Conference, San Diego, California, 5662.

HadjArab A. (2004). Loss of load probability of photovoltaic water pumping systems, 76(6): 34-39.

Hindmarsh J. (1977). Electrical machines and their applications. Pergamon Press, Third edition.

Hsiao Y.R., Blevens B.A. (1984). Direct coupling of photovoltaic power source to water pumping system, Solar Energy, 32: 489-498.

Kenjo T. and Nagamori S. (1985). Permanent-magnet and brushless DC motors, Clarendon press-Oxford.

Demetrio L. (2014). SPICE modelling of complete photovoltaic system including modules, energy storage elements and a multilever inverter, Solar Energy, 107: 78-83.

Kung D. (2014). A simplified model for photovoltaic modules based on improved translation equations, Solar Energy, 101: 23-28.

Lujara N.K. (1999). Computer aided modelling of systems for solar powered water pumping by photovoltaic, D.Ing thesis, Rand Afrikaans University, Ch 1, 1-20, Ch 2, 21-62.
Lujara N.K., van Wyk J.D. and Materu P.N. (1999). Loss models of PWM inverters in photovoltaic applications, Proc. ICEET 99, University of Dar es Salaam, Tanzania, 34-40.

Lujara N.K. and Materu P.N. (1997). A direct-coupled DC motor drive water pumping system with improved performance, Uhandisi Journal, 21(3): 36-49.

Lynch B. and Salameh Z. (1988). High precision electro-optically controlled dual axis sun tracker, The Eighth European Photovoltaic Solar Energy Conference, Italy, 67-74.

Moshov D.M. (1977). The advantages of sun tracking for planar silicon solar cells, Solar Energy, 19: 91-97.

Mohan N., Undeland T.M. and Robbins W.P. (1995). Power electronics: Converters, Applications and Design, John Wiley \& Sons Inc.

Bion N. (2004). Comparison of performance of PV water pumping systems driven by fixed, tracking and V-trough generators. Solar Energy, 76(6): 36-42.

Roger J.A. (1979). Theory of direct coupling between dc motors and photovoltaic solar arrays, Solar Energy 21: 93-198.

Say M.G. and Taylor E.O. (1982). Direct Current Machines. Pitman Books Limited, 1982.

Severns R. (1984). Hexfet characteristics manual, Application Note 942 A. 